\title{
Quality Upgrading of the Manufacturing Industry in Supply-Side Structural Reformation
}

\author{
Zhang Gang
}

State Administration for Market Regulation, Beijing 100088, China

\begin{abstract}
Quality in manufacturing reflects the core competitiveness of enterprises and industries and the national comprehensive strength. This study focuses on the main direction of supply-side structural reform, analyzes the role of upgrading manufactural quality in processing to provide impetus to industrial transformation, optimizing the employment structure, promoting coordinated economic development, and building the national brand. The author maintains that quality, which covers aspects of both hard and soft powers, should be strengthened like science and technology and education, and granted comprehensive status. Based on the concept of "Big Quality," six aspects for accelerating reform in upgrading manufactural quality are put forward: set goals for engaging quality with efficiency, create new methods for industrial structure analysis of quality dimensions, build new advantages of national quality infrastructure, implement major projects for quality upgrading, innovate the law and policy systems of quality upgrading, and strengthen the work system of "Big Quality."
\end{abstract}

Keywords: supply-side structural reformation; manufacturing industry; quality upgrading

High quality is an important symbol of a strong manufacturing industry. Quality reflects the core competitiveness of enterprises and industries, as well as the national comprehensive strength. The overall quality level of China's manufacturing industry is not sufficiently high to meet the increasing domestic consumption demand or to adapt to the intensifying international competition. It was clearly put forward at the Central Economic Working Conference in December 2006 that the main line of China's economic development is to undertake supply-side structural reform, the main orientation of the supply-side structural reform is to improve the supply quality, and the central task of supply system enhancement is to comprehensively improve both product and service quality. Under new circumstances, to have a deep understanding of the supply-side structural reform and execute decisions of the Party Central Committee and the State Council concerning this reform, we need to reconsider the significance of quality upgrading of the manufacturing industry and re-explore methods for the same.

\section{Quality upgrading of the manufacturing industry forms the core of the supply-side structural reform}

The quality of supply depends on the quality of the manufacturing industry. The quality upgrading of the manufacturing industry plays a vital role in promoting industrial structure transformation, employment structure optimization, coordinated economic development, and national brand building, and directly concerns optimization of the supply structure and enhancement of the supply efficiency.

\subsection{Promoting industrial structure transformation}

Industrial structure transformation should play "dual-wheel driving" roles of technological innovation and quality promotion. Innovation leads to reforms in technology, management, methods, and modes, and it serves as a power source for the

Received date: April 25, 2017; Revised date: June 7, 2017

Corresponding author: Zhang Gang, State Administration for Market Regulation, Professor of Engineering, State Department counselor. Major research field is macro-quality management. E-mail: zhangg@aqisq.gov.cn.

Foundation program: CAE Advisory Project “Research on Industrial Foundation Strengthening Strategy” (2014-ZD-10).

Chinese version: Strategic Study of CAE 2017, 19 (3): 029-038

Cited item: Zhang Gang. Quality Upgrading of the Manufacturing Industry in Supply-Side Structural Reformation. Strategic Study of CAE, https://doi.org/10.15302/ J-SSCAE-2017.03.005 
reforms. Quality concerns precision, reliability, and uniformity, and constitutes the competitiveness. Technological innovation and quality promotion supplement and promote each other and act together to form a sustainable productive force (Fig. 1). At the backdrop of industrialization, innovation support would be crucial to the creation of a value multiplication effect through quality, and it would also be essential to realize the significance of innovation and reflect in quality upgrading endeavors. In this sense, manufacturing quality upgrading is a direct form of expression for optimization and transformation of the industrial structure.

Industrial structure transformation has rich connotations. In terms of production factors, structural transformation refers to the transformation of labor-intensive industries to capital-intensive and technology-intensive industries. In terms of technical content, structural transformation refers to the transformation of

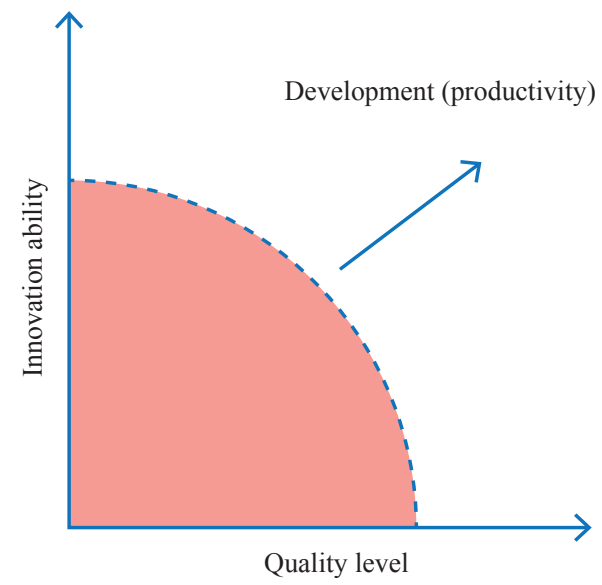

Fig. 1. Innovation and quality contribute to sustainable development. low-tech industries to medium-tech or high-tech industries and in terms of quality elasticity, structural transformation refers to the transformation of price-sensitive industries to price-quality neutral type industries and quality-sensitive type industries. Two cardinal directions of quality upgrading are intra-industry quality upgrading and inter-industry quality upgrading that are correlated with product quality structure and industry quality structure, respectively.

The product quality structure reflects the distribution of products of varying quality levels in the economic structure, defines competitive positions of the products, and effects the economic growth of a nation. To a large extent, the quality level defines the average unit price of products exported. For a long time, the average unit price of China's industrial products exported has not only been lower than that of major industrial countries but also lower than that of the world average (Fig. 2). According to a calculation by the quality effective research center of the former General Administration of Quality Supervision, Inspection and Quarantine of the People's Republic of China, for the last ten years, in the field of equipment products, the average unit price of China's mechanical and electrical products exported was 20.95 US dollars per kilogram. This is far below Japan's average of 42.12 US dollars per kilogram. Additionally, the average unit price of track traffic products exported was 3.52 US dollars per kilogram, far below Germany's average of 13.54 US dollars per kilogram. In the same period, in the field of consumer goods, the average unit price of leather products exported was 9.36 US dollars per kilogram, far below France's average of 64.81 US dollars per kilogram. Additionally, the average unit price of headwear products exported was 23.89 US dollars per kilogram, far below Italy's average of 62.04 US dollars per kilogram. In 2015, China's

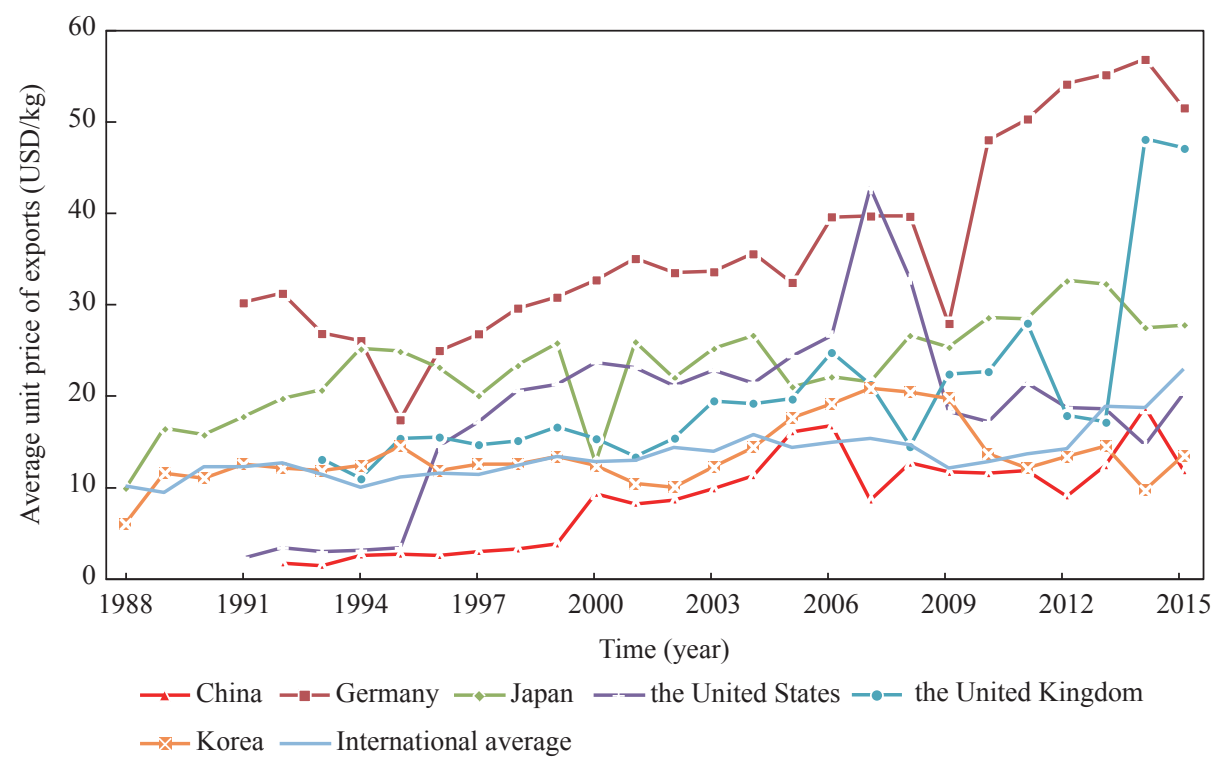

Fig. 2. Comparison of average unit price of industrial products exported of major countries. 
accumulated export commodities reached $4.41 \times 10^{9} \mathrm{t}$, which is 3.74 times that of Germany $\left(1.18 \times 10^{9} \mathrm{t}\right)$. However, the amount of exports of China was only 1.23 times that of Germany. China's manufacturing industries are now mostly at the lower end of the global industrial chain, and both traditional industries and strategic emerging industries are facing the prominent problem of low quality competitiveness. Among the export products of China, in 2005, the ratios of high-quality goods and low-quality goods were $32.42 \%$ and $45.90 \%$, respectively, while Germany's were $87.08 \%$ and $2.55 \%$, respectively, which shows big gaps in quality orientation and quality status in the industrial development of the two countries. The European Competitiveness Report 2010 by the European Commission points out that quality upgrading and high-quality goods contributed toward enhancing the market competitiveness of some countries in the European Union. It also helped these countries cope with economic recessions, and thereby supported economic stability and growth.

An industry's quality structure reflects the presence of quality-elastic industries (which are industries whose sales are considerably influenced by the quality factor and which are high in both price and sales) in a national economy and also reflects the significance of quality competition within different industries. An industry's quality structure further comprises quality-sensitive industries (for example, airplane and precise instrument industries), price-sensitive industries (for example, the textile and clothing industries), and quality-price neutral industries (for example, the beverage industry). Take the textile and clothing industry as an example. As a price-sensitive industry, the textile and clothing industry pursues a lower price with the same quality. In terms of long-term development, it has been observed that the geographical movement of the textile and clothing industry has been towards low-cost manufacturing bases across the globe, from the UK and Italy to Japan and Korea and subsequently to China. At present, with an increase in China's labor cost, the textile and clothing industry tends to move from China towards Southeast Asian countries that incur lower costs, such as Vietnam. For the price-sensitive industries, quality upgrading provides an opportunity for a more eco-friendly and diverse development with higher standards and higher quality, which is vital to structural transformation and long-term development of many traditional labor-intensive industries of China. However, the situation for the quality-sensitive industries is quite different. As Apple Chief Executive Officer Tim Cook said, Apple's layout and production in China was based not on cost, but on the skilled talent pool and the quality factor in the industrial chain layout.

To sum up, the quality upgrading of the manufacturing industry is an important means for industrial structure optimization and economic transformation. Among the traditional industries, the lower-end industries can be upgraded to become high-end industries through quality upgrading, and thus can better adapt to increasing consumption demands at home and abroad. Concerning the strategic emerging industries, through the dual-wheel driving role of technological innovation and quality upgrading, high-tech fields (such as photovoltaic, graphene, and new-energy vehicle industries) can be protected against a low-end tendency, thereby enhancing the quality of industrial development.

\subsection{Promoting employment structure optimization}

Quality upgrading of the manufacturing industry and technological advancement are now triggering employment structure reforms worldwide. For a long time, at the backdrop of economic globalization, developed countries have arranged their production units globally, based on costs, and have made significant profits through quality, technology, management, and brand superiority, while developing countries have gained employment growth and economic development by participating in global trade divisions with a low-cost advantage. However, in recent years, with scientific progress and quality promotion, labor-saving technological changes, represented by automatic and intelligent factories, have developed and grown stronger. Meanwhile, there has been a constant decline in the ability of many traditional labor-intensive industries to absorb the labor force, thereby leading to the disappearance of a large number of traditional jobs. A survey by the Washington Post in 2016 showed that the reappearance of manufacturing industries in developed countries had contributed toward an increase in employment posts. However, the increase was not proportional across the employment posts in the manufacturing industries, and certain employment posts are not expected to reappear. Importantly, with the progress of the labor-saving technology, the emphasis on labor cost in the global industrial layout has certainly reduced. In other words, production strategies have ceased to emphasize the principle of obtaining the lowest costs or establishing units in areas with adjoining raw material sources. A new global trade system based on market prosperity and promotion of domestic employment has emerged into the scene and domestic manufacturing and consumption are expected to become the commonplace requirements for manufacturing development.

Adjustments in global manufacturing patterns are now challenging traditional employment modes and structures. Currently, developed countries, such as the United States, are focusing on the return of domestic enterprises at the national level, by accepting native customers and employees to the full extent, and thereby serving domestic economic and social development and building new employment patterns. Multinational enterprises have moved their production and assembly lines, successively, back to their home countries or locations close to the home markets to facilitate proximity between their production and service units and customers, and to respond to customer needs with a quicker supply rate and a stronger customization ability. The global trade division reforms have brought about redistribution of employment posts and have driven employment growth and externally oriented economic development of countries with 
abundant labor resources, such as China. However, currently, concerning developing countries, their development pattern of integrating into the global value chain with processing trade now face unprecedented challenges, and it is also expected that the industrial transfer will lead to a loss of employment posts. Statistics show that, for the first three quarters of 2016, the value of import and export of China's processing trade declined by $7.0 \%$ on a year-on-year basis and accounted for $29.4 \%$ in the value of import and export, a decline by 1.6 percentage points from the corresponding period in 2015 . This led to a consequential decline in the ability of the processing trade to absorb employment posts. For a further period of time, owing to the increasing employment pressures in China, there is a need to optimize the employment structure.

Quality upgrading of the manufacturing industry has become crucial for facilitating the optimization of the employment structure. Studies by the United Nations Industrial Development Organization (UNIDO) show that the rebuilding of the global competitive landscape drives the developing countries to upgrade their industry's quality and core competitiveness. The absence of rebuilding initiatives would lead to premature deindustrialization, low productivity, the growth of informal service industries, and slim growth potential [1]. Concerning China, quality upgrading of the manufacturing industry can lead to strengthening the core competitiveness of the manufacturing industry, creation of employment posts, and optimization of the employment structure. Specifically, the advantageous effects of quality upgrading of the manufacturing industry can be summed up as follows. First, quality upgrading facilitates the realization of product innovation, generation of new economic activities and industries, and absorption of labor into a high-end labor market. For example, large civil aircrafts (such as homemade large aircraft C919) with real commercial prospects have been developed by relying on quality upgrading of civil aircrafts. Additionally, the increased global demand for civil aircraft has resulted in market competition among major players like the Boeing Company, the Airbus ASA, and the likes, thereby increasing the economies of scale. In another case, the enhancement of the quality of innovative products, such as robots and civil unmanned aerial vehicles, in recent years, has increasingly promoted international competitiveness of China's consumer electronics industry and rapidly increased new high-end employment posts. It is estimated that China's installed industrial robots will break 1 million by 2020 and the demand for talents with professional skills will reach 3 million. Second, quality upgrading has facilitated the transformation of low-end industries to high-end industries; enhanced the competitiveness by means of advanced technology, high-quality, good management, and excellent brands; and expanded and bolstered the manufacturing industry, thereby increasing the number of employment posts. For example, in terms of import and export, higher-level employment growth can be boosted through quality improvement of the general trade. Sta- tistics show that, for the first three quarters of 2016, the quality promotion of China's export products led to an increase in the value of general trade goods exported by $0.1 \%$, and it accounted for $56.0 \%$ in the export trade, an increase by 1.1 percentage point from that of the corresponding period in 2015. It can be predicted that a higher-level employment growth can certainly be boosted by advancing product quality upgrading of the general trade. Third, quality upgrading can facilitate effective exploration of the accumulated technological advantages and demand potential of China's domestic market and increase the number of employment posts in the process of undertaking new international industrial transfer. With accelerated upgrading of the demand for quality and of the consumption structure, China has become the main consumer market in many fields all over the world. Considering car consumption, China's new volume of car sales exceeded 28.02 million in 2016, with the year-on-year growth rate reaching $13.65 \%$. Owing to the new car sales volume, China has been ranked as the world champion for 8 years continuously and is 10.48 million and 13.38 million higher than that of the United States and the European Union, which ranked number two and three, respectively. It is essential for countries like the United States to move their production units back to their home markets, shorten supply chains, and set-up supply chains closer to the Chinese market. New international industrial transfer will certainly bring along optimization of the domestic employment structure and a higher level of employment growth [2].

China should focus on the optimization of the employment structure by quality upgrading of the manufacturing industry. Quality upgrading of the manufacturing industry will help in the promotion of the technical content of the industries and improve structures of export goods, and thereby increase the requirements for highly skilled workers. Although quality upgrading pushed forward by digitized, networked, and intelligent production mode reforms might cause reduction of some employment posts, newly-created employment posts have promoted higher-end employment at a higher level [3], enhancing labor productivity. This has raised the employment levels as a whole and optimized the employment structure, which is an important connotation of enhancement of the supply system.

\subsection{Promoting coordinated economic development}

China's manufacturing industry has been facing a quality crisis and it has also hampered the country's economic development. Research results of the Manufacturing Power Strategic Study Group showed that, in comparison to the manufacturing power comprehensive indexes of the United States, Germany, Japan, the United Kingdom, France, Korea, India, Brazil and China, the United States ranked at the first place, Japan and Germany followed closely, and China lagged behind. Especially, in terms of the quality benefits indicator of the manufacturing power comprehensive indexes, China's number was far lower than 
that of the main developed countries (Fig. 3), which is also one of the main reasons why China's manufacturing industry is large but not strong. Among the four first-grade indicators of China's manufacturing power comprehensive indexes, the quality benefits indicator ranked at the bottom and contributed the least. In 2005 , the quality benefits indicator of China was only 12.62 , and only accounted for $12.51 \%$ of the comprehensive index score. Low quality benefits slowed the development and reduced the stability of the manufacturing industry and China's economy as a whole (Fig. 4). The manufacturing quality competitiveness index was the same as the aforementioned index, and the local economic development level of every province, autonomous region, and direct-controlled municipality of China was also dismal.

Quality upgrading of the manufacturing industry is now becoming the main driving force for further economic growth. The main consumer markets around the world have already entered a quality-focused era wherein the main developed countries in Europe and the US regard quality upgrading as the key factor for developing the manufacturing industry and promoting economic growth. The European Union introduced a series of political documents, such as CARS 2020 Action Plan, Action Plan for Fashion and High-end Industries, and Steel: Preserving sustainable jobs and growth in Europe, successively. Additionally, the European Union proposed taking additional trade remedy measures and import priority supervision measures based on the implementation of 37 anti-dumping and countervailing measures for imported steel products. The European Union also proposed a focus on promoting innovation and quality competitiveness of the manufacturing industry, thereby enhancing important links for strengthening the traditional industries and competitiveness of advantage industries on technology, quality, brand, and envi-

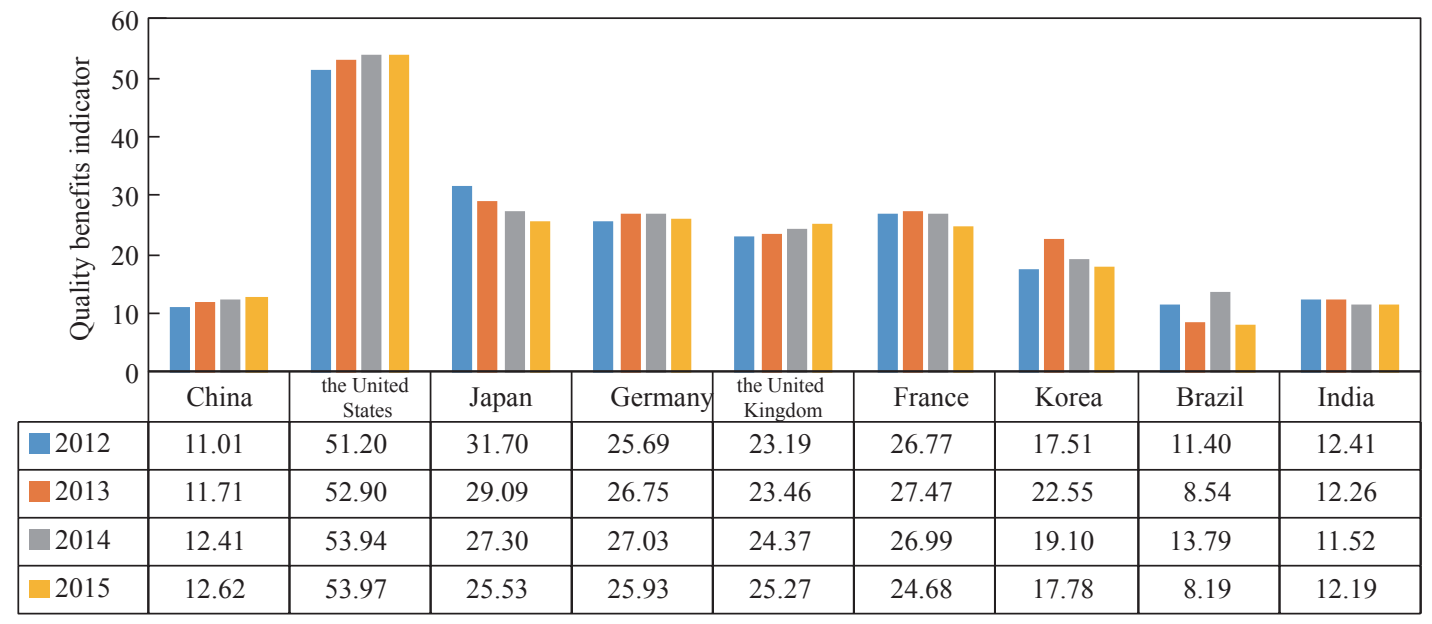

Fig. 3. Comparison diagram of quality benefits indicators of the nine manufacturing powers from 2012-2015 [4].

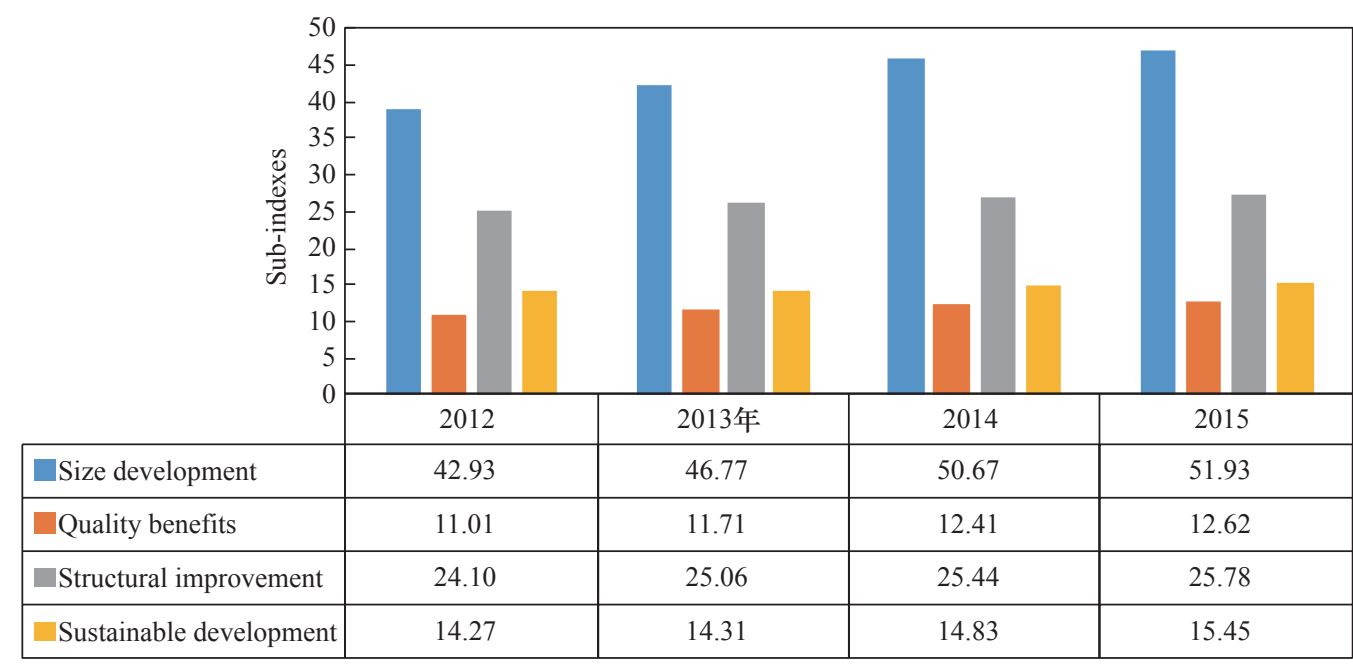

Size development

Quality effectiveness

Structural improvement

Sustainable development

Fig. 4. Comparison diagram of China's manufacturing power sub-indexes from 2012-2015 [4]. 
ronment protection. The goal of the manufacturing industry of the United States is to rebuild sustainable competitiveness centering on innovation and quality. In 2012, the United States increased 8 billion US dollars in the annual budget proposed in the National Strategic Plan for Advanced Manufacturing to support the partnership between the nation, community colleges, and enterprises, and to promote workers' skills in manufacturing industries and the promotion of growth-type industries. The United States has founded the Advanced Manufacturing National Program Office (AMNPO) and set it up in the National Institute of Standards and Technology (NIST). The purpose of this organization is to strive to achieve an integration effect of technological innovation and quality promotion. With the implementation of these policies, the manufacturing capability is stimulated and enhanced, and the United States is very likely to become the 'World Factory' again. By driving innovation and upgrading quality, the manufacturing capability of major advanced countries in Europe and America has been continuously promoted to realize sustainable economic development.

Quality upgrading supports coordinated and balanced development of the national economy. China's central and western areas have advantages in the aspects of resource abundance and labor cost, and these aspects enable the central and western parts to dominate the labor- and resource-intensive industries of the eastern area of China. However, nationwide, the effect of industrial gradient transfer is not ideal. One of the important reasons to which it can be attributed to is that all the supporting facilities of the industry chain are weak, and hardware and software conditions for quality upgrading are insufficient. The evaluation result of manufacturing quality competitiveness of some provinces, autonomous regions, and direct-controlled municipalities of China in 2015 showed that the manufacturing quality com- petitiveness of the central and western regions and the northeast region was obviously lower than that of the eastern region, and manufacturing quality competitive indexes of the regions and the GDP per capita of the regions were highly homodromous (Fig. 5). The manufacturing quality competitiveness indexes of the eastern, central, western, and the northeast regions were $87.48,82.97,82.10$ and 81.45 , respectively. These indexes show a gradient array that is high in the east and low in the west. Concerning the competitiveness of export goods in the international market, in the first three quarters of 2016, the ratio of the foreign trade of the western region to that of the whole country was $7.0 \%$ and it has been witnessing a continual decline. As far as exports are concerned, witnessing a year-on-year reduction of $16.0 \%$, the exports of the western region amounted to 746.25 billion Chinese Yuan, a reduction of over 140 billion Chinese Yuan compared to the same period in 2015. In the stated year above, the general trade exports reduced by $26.2 \%$ on a year-on-year basis, and the exports of processing trade and labor-intensive products reduced by $1.9 \%$ and $26.6 \%$, respectively. Therefore, an emphasis on the supply quality and acceleration of the quality upgrading according to local conditions and industries are important measures that can narrow regional disparities and promote coordinated development of regional economies. Additionally, it will also be essential to improve the supply-side structural reforms.

\subsection{Promoting national brand building}

A brand can enhance its image and popularity only through high quality. The design and quality of products and services convey crucial messages about a country to global consumers. The United States has a dominant status in world manufacturing

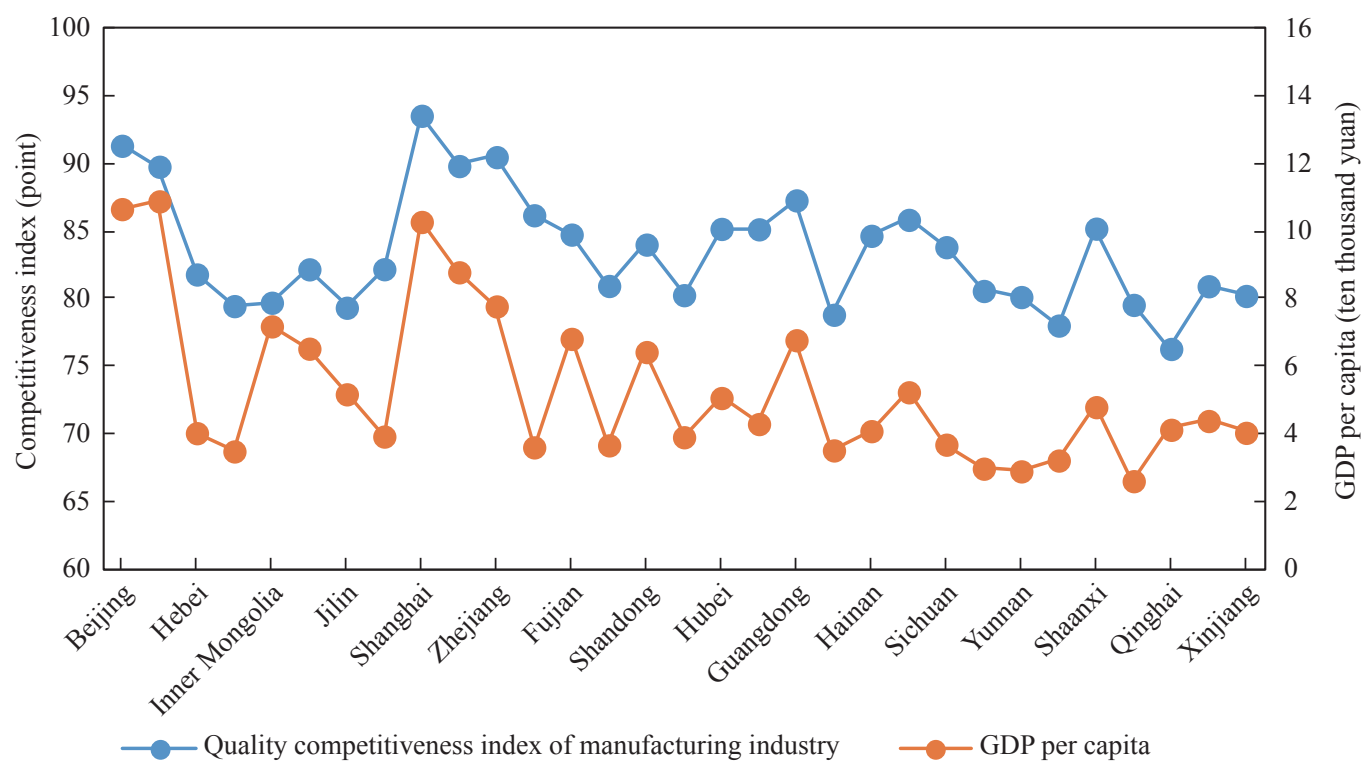

Fig. 5. Comparison of manufacturing quality competitiveness indexes and GDP per capita of some provinces, cities, and autonomous regions in China. 
owing to its globally influential quality theories and practices, such as zero-defect control, six sigma management, and the performance excellence model (national quality awards). Additionally, Japanese products and brands have gained a high reputation worldwide because of their high quality, and Japan's lean thinking, craftsmanship, management ideas, and culture of excellence have become a focus for global scholars to research and for enterprises to learn. Concerning Germany, the "Germany, manufacturing quality first" principle is the prime reason behind the global sales of the German-manufactured products. Additionally, products manufactured by the hidden champions in Germany, craftsmanship, and the contribution of the dual-track education system have enhanced the quality delivered by the German manufacturing industry. These factors have contributed to high consumer demand for German products. In addition, the above countries pay high attention to the overall construction of national quality infrastructure, which shows their capability of establishing and deriving the desired outcome from quality management systems. Therefore, strong national brands of the United States, Japan, and Germany are built by relying on high quality. As the Financial Times Deutschland reported, the marketing expert Simon Anholt evaluated the values of national brands "made in the US," "made in Japan," and "made in Germany" with the help of global market research companies, the values being 17.9 trillion, 6.2 trillion and 4.5 trillion, respectively.
The disadvantage of China's national brand building is mainly the low overall quality level. As per a domestic brand general impression survey conducted in 2005 among 3460 domestic consumers by Huanqiu.com and PollChina Research Center, 28.4\% of the domestic consumers considered homemade brands to be of low quality and $3.6 \%$ of the domestic consumers said that they had a very bad impression of homemade brands and refused to use them. The 2015 China National Image Global Survey conducted by China Foreign Languages Publishing Administration showed that quality was still the primary factor, accounting for over $60 \%$, for hindering overseas development of China's manufacturing. The developed countries considered Chinese goods to be of low quality, $63 \%$ of interviewees in the developed countries considered that goods made in China had several quality issues, and $63 \%$ of interviewees in developing countries considered goods made in China to be substandard in quality. Surveys on credit check of goods made in China, the United States, and Japan by the World Brand Lab showed that positive expressions of brands made in China were obviously inferior to that of the United States and Japan (Fig. 6). The belief that goods made in China are low in quality, grade, pricing, and credibility has not fundamentally improved.

China should accelerate the pace of manufacturing upgrades and the national brand building process. The world industrial history reveals that countries, such as the United States, Japan,

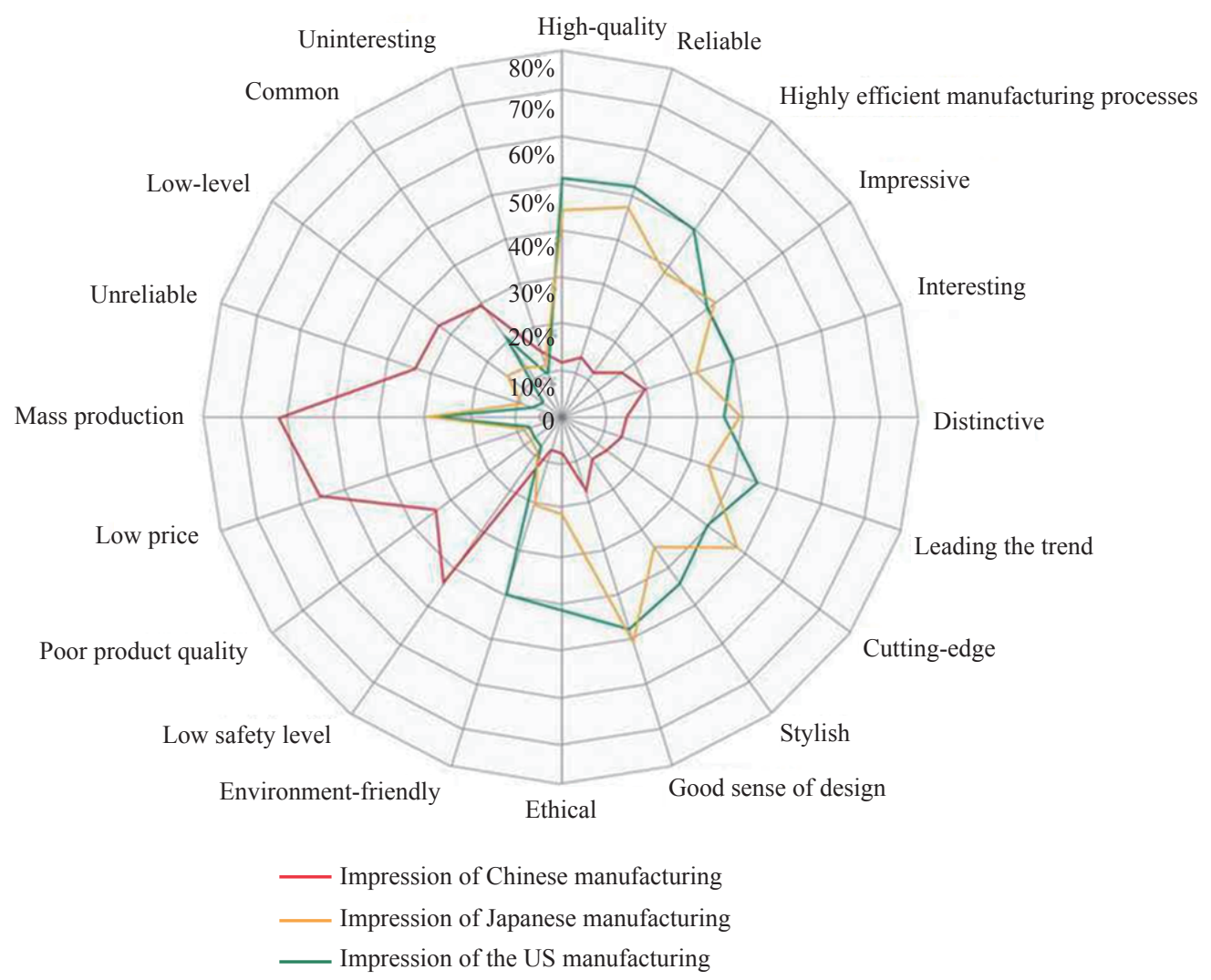

Fig. 6. Product credit investigations in China, the United States, and Japan by World Brand Lab. 
and Germany have all experienced the course of quality revolution or quality lifting movements, cultivated many enterprise and industrial brands in the process of quality upgrading of the manufacturing industry, built national brands, and established their competitive strength globally. Currently, considering the features of industrial development in China, China must shift its focus from manufacturing to innovation, speed to quality, and product-centric to brand-centric in order to release itself from the middle-income country trap. In the background of globalization, promoting lifting of the overall quality level and cultivating strong national brands to meet consumption demands and adapt to market competition is just the main orientation of the supply-side structural reform.

\section{Driving quality upgrading of the manufacturing industry by supply-side structural reforms}

The overall quality level of China's manufacturing industry is not high. One important reason for this situation is that China's modern industry development has failed to be a part of an adequate industrialization process. Concerning the aspect of quality development in China, China lacks in innovation ability, technological reserve, and talent teams. Additionally, the country's cultural accumulation is not profound and legal construction lags behind. Although China has invented the world-famous China Speed and realized quantity-scale accumulation since the reforms and opening-up policy was carried out more than 30 years ago, the country's low-quality levels subdue these accomplishments. In the process of transitioning from a major manufacturing country to a globally leading manufacturing power, China must adhere to the quality-first orientation, understand the main directions of the supply-side structural reform, innovate, and take comprehensive measures in line with the Big Quality concept. These steps will enable the country to solve prominent issues in the industry and establish a sustainable long-effect mechanism.

\subsection{Setting a prominent goal for quality-benefit type development}

Currently, the key indicators for evaluating the quality status of the manufacturing industry are the manufacturing quality competitiveness index, qualified rate, spot check qualified rate, and export commodity failure rate. These indicators play an important role in supporting the promotion of a product's quality and advancing quality development. However, on the whole, because the quality indicators reflect only a product's terminal result and cannot reflect the role of quality in raising the total factor productivity or inner relationship between quality and benefits, investments for improving quality by enterprises, industries, the government, and the society are insufficient. The quality-promoting mechanism is hard to maintain and hence quality improvement is reduced to a mere idea or slogan. To implement the strategic decision of focusing on the development of quality and benefits, we must develop a close connection between quality and benefits and form a scientific goal orientation and assessment mechanism at the national level.

For many years, many enterprises and research institutes have conducted examinations to set up some quality-benefit indicators at a micro level, such as the quality loss rate, the quality contribution rate, and the ratio of profits to cost. In recent years, some research institutes have made breakthroughs in researching the definition, connotation, measurement models, and improving paths of macro quality benefits (of the manufacturing industry) and proposed a corresponding indicator system (Fig. 7). These researchers are now developing a macro quality benefits analysis system based on big data support. On this basis, China should accelerate transformation and application of scientific research achievements; build an indicator system; establish a link between quality and benefits; and unify the goal and the route. Additionally, China must enable the enterprises, industries, the government, and the society to become conscious of quality pro-

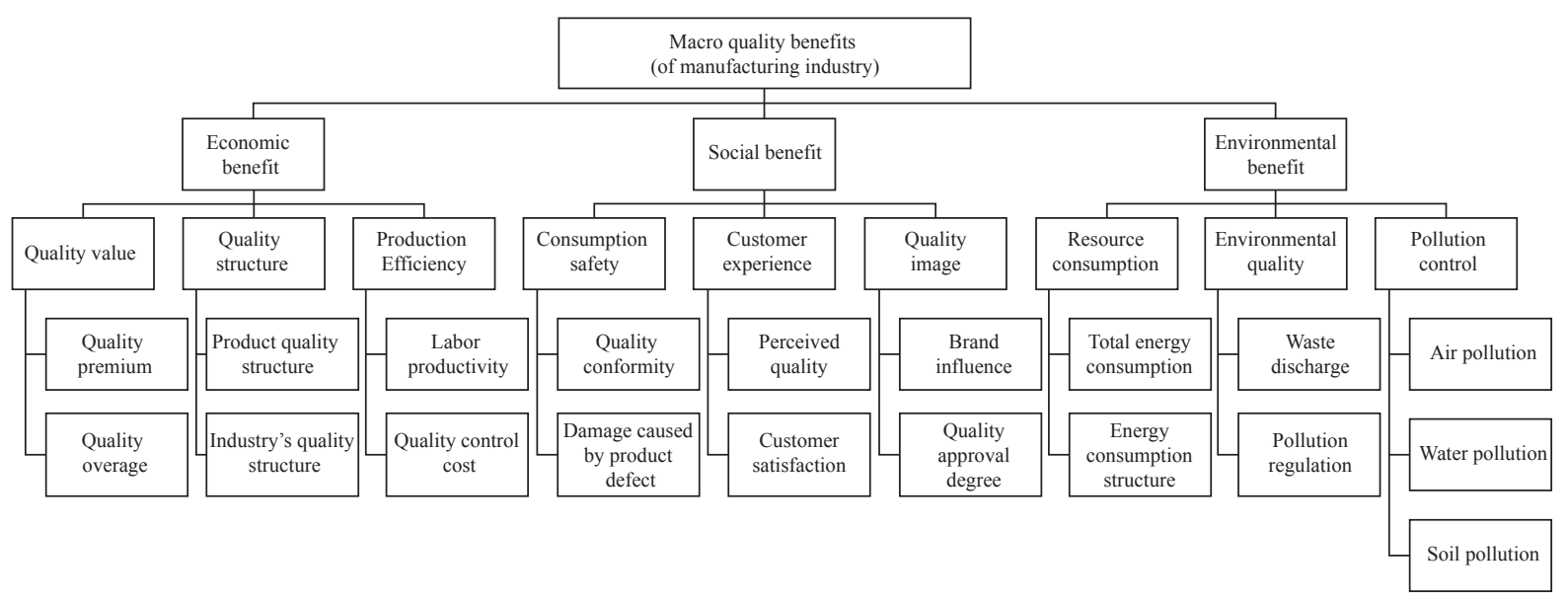

Fig. 7. Framework of an index system for evaluating macro quality benefits (of manufacturing industry). 
motion from the perspective of a scientific indicator system; pinpoint paths for quality upgrading; inject sustainable dynamism into quality development; and enable quality upgrading of the manufacturing industry to achieve more with less.

\subsection{Creating a new industrial structure analysis method with a quality dimension}

It is challenging to define high-, middle-, and low-end industries using the current industrial structure analysis methods. China is now using two methods for industrial structure analysis. The first method is a ratio analysis of primary, secondary, and tertiary industries. This method is geared to international standards and it reflects the structural distribution of the national economy. However, it is challenging to ascertain the state (such as high-, middle-, and low-end of industries) of the industrial development level by using this method. The second method is an analysis of traditional and strategic emerging industries. This method reflects the development course of emerging industries, but is hard to precisely analyze high-, middle-, and low-end situations of the industries using this method because the divisions and definitions of the traditional industries and the strategic emerging industries are still unclear. Therefore, the above two industrial structure analysis methods cannot comprehensively or precisely show the industrial structure status or optimized orientations and paths.

In this regard, the formulation of a new industrial structure analysis method with a quality dimension should be accelerated. The Center for European Economic Research began to study a new method for analyzing the industrial structure with the quality dimension in the early 1990s. The new method categorized the industries into quality-sensitive industries, quality-price neutral industries, and price-sensitive industries. The quality-sensitive industry is particularly sensitive to quality; demands achievement of high quality and large investments for quality improvement; involves equipment usage, technological innovation, management capabilities, technician quality, or cultural construction that can obtain a very high added value. It also comprises manufacturing industries, such as aeronautics, chip, and precise instrument industries. The quality requirements of price-sensitive industry can be easily met. This industry participates in market competition mainly by price. The examples of such industry are plastic product and packaging container manufacturing industries. Research results by related European institutions showed that the ratios of quality-sensitive industries in major industrialized countries, such as the United States, Japan, and Germany exceeded $40 \%$. However, this ratio in China is lower than $17 \%$. Through the new industry structure analysis method with the quality dimension, a high-, middle-, and lowend industry structure can be defined, and paths transitioning from middle- and low-end industries to middle- and high-end industries can be analyzed.
China is now at a critical stage of transitioning from a large manufacturing country to a leading manufacturing power. By creating a new industry structure analysis method with the quality dimension, the enterprises, industries, the government, and the society can be better guided to increase their investments in quality improvement. This method can also contribute toward accelerating the process of intra-industrial quality upgrading and inter-industrial quality upgrading and promote the supply-side structural reform focusing on supply quality.

\subsection{Enhancing construction of national quality infrastructure}

In 2005, the United Nations Conference on Trade and Development (UNCTAD) and World Trade Organization (WTO) first proposed that metrology, standardization, and conformity assessment (certification and accreditation plus inspection and detection) constitute the concept of National Quality Infrastructure (NQI). Subsequently, the United Nations Industrial Development Organization (UNIDO) and International Standardization Organization (ISO) stated that metrology, standardization, and conformity assessment would form the three pillars of global economic and social development in the future. The above positioning is based on the following respects. First, NQI supports innovation, serves as the carrier for transformation and application of achievements, and plays an increasingly noticeable role in this new round of technological revolution. Second, NQI supports technical exchange and cooperation and facilitates trade, and it has become an indispensable premise in the context of economic globalization. Third, NQI reflects the multiplication effect of a factor integration role, and reflects the scientific law in which metrology, standardization, certification and accreditation, and inspection and detection contribute to the industry and value chains.

China is now at a critical juncture of economic transformation and development. To realize the goal of upgrading the quality of manufacturing industry and to strengthen the foundation for a sustainable economy, the construction of the national quality infrastructure must be enhanced. To this end, the layout for positioning the quality infrastructure must be strengthened and the construction of the quality infrastructure must be wellplanned. First, at the national level, the key scientific and technological program "research on and application of generic technology of national quality infrastructure" should be continuously implemented. This will enable the endeavors toward a larger theoretical and practical breakthrough. An overall construction mechanism of metrology, standardization, certification and accreditation, and inspection and detection should be created, and integration of information, technology, service, and systems should be realized, thereby formulating a 'China plan' for construction of the national quality infrastructure. Second, at the industrial level, by centering on upgrading the traditional indus- 
tries and developing emerging industries, a number of national-level NQI application demonstrating bases should be founded. Orientation and functions of national quality testing centers, metrology testing centers, and national technical standard innovation centers should be optimized, integrated, and comprehensively promoted. Quality-leading enterprises and industries should be supported to acquire new advantages in international competition. Third, at the regional level, local governments should be encouraged to build several business-collaborating and service-efficient NQI service platforms. Additionally, support should be provided to a large number of mid- and small-sized enterprises existing in broad areas for promoting their quality and efficiency and for upgrading them, thereby promoting high-quality development of economies with local characteristics.

\subsection{Implementing major projects for quality upgrading}

A new round of technological revolution and industrial transformation will bring about disruptive reforms for the development of global manufacturing industries and will also profoundly affect innovation in quality technology and quality management. To overcome the quality issues in the manufacturing industry, China must focus on key fields, stick to innovation, optimize support conditions, combine government support with market operation, and implement major projects for upgrading the quality of the manufacturing industry.

China should implement high-quality manufacturing projects by developing major equipment and considering national interest, people's livelihoods, and hot consumer goods, as a starting point. For example, by focusing on precision, reliability, and uniformity of key functional components, China can implement a numerical control machine quality upgrading project; by focusing on improving reliability of bearings, wheel sets, and braking systems, China can implement a quality promotion project of key components of high-speed rails; by taking high-quality chips as a breakthrough point, China can implement a core component standard breakthrough project for communication mobile devices; by focusing on solving the quality bottlenecks in manufacturing facilities, China can implement a high-end detecting instrument and medical equipment localization project; by focusing on improving precision and the service life, China can implement an automobile steel sheet quality uniformity project. To achieve serviceability and uniformity of middle- and high-end consumption, China can implement an international comparison project for household electrical appliances. Additionally, by aiming at realizing effective quality control of the whole industry chain and by improving middle- and high-end consumer perception, China can implement an infant formula milk quality stability project. Through implementation of high-quality manufacturing projects, quality breakthroughs can be realized in key fields and new advantages for quality competition can be made.

Aiming at creating competitive advantages and optimizing the development environment, China can implement a number of comprehensive projects for promoting quality upgrading. For example, to adapt to manufacturing reforms against the background of digitization, networking, and intelligence, China can implement demonstration projects for quality technology and quality management innovation. By employing big data analysis and integrating cross-sector and cross-industry quality information resources, China can implement a construction project of information platforms for real-time analysis and comprehensive evaluation of manufacturing quality. With an aim to serve the "One Belt and One Road" strategy, China can implement bilateral and multi-lateral cooperation in metrology, standardization, certification and accreditation, and inspection and detection, and push forward interconnecting, interworking, and mutual-recognition projects; by focusing on industry cluster districts, national innovation demonstration zones, and high-tech industrial parks, China can allocate its national management resources on the whole and implement a construction project on regional brand demonstration zones. By effectively tracking, researching, forewarning, evaluating, and coping with technical trade measures, China should support its manufacturing industries to move out of its limited scope and accelerate the construction project for a nationally uniform, resource-sharing, and sensitive technical trade measurement system. Additionally, by considering the idea of promoting craftsmanship and adhering to honesty, China can implement multi-dimensional, multi-level, highly-penetrable, and widely-influential cultivating projects for the building of a quality-centric industry. Through implementation of the comprehensive projects, solid foundations in technology, management, and environmental conditions can be laid for sustainable development of China's quality.

\subsection{Creating institution and policy systems for quality upgrading}

China should take institutional and policy innovation as a driving force to create an ecological environment in favor of quality innovation and quality promotion, thereby inspiring the initiatives of enterprises. Currently, breakthroughs need to be made first in the aspects of legal construction, fiscal and taxation support, and personnel fostering.

Quality legal construction should be perfected. Quality promotion laws should be formulated. This will help to establish motivating, guiding, and protecting systems for quality innovation. An evaluation mechanism for China's quality awards should be established and positioned. It will also cultivate and protect brands and allow brand value evaluation as per the law. Additionally, it will establish quality credit information collection, management, evaluation, and admission systems, and 
thereby promote construction of a quality credit system, promote the marketization process of quality services, and standardize quality intermediary services. Therefore, it will allow the construction of a legal environment where high quality is paid by high price, and quality is decided by votes. It will also enable the formulation of quality liability laws and construction of a product quality accountability system, which takes civil compensation as the main body, administrative penalties as compensation, and criminal responsibility investigation as the backing.

Fiscal and taxation support should be scaled up. Systems should be established for quality-leading enterprises and standard-innovating enterprises to allow these enterprises to enjoy supportive finance, tax, and talent policies for high-tech enterprises, thereby promoting and implementing a "leading runner" system for enterprises with advanced standards. Specialized funds for national quality development should be set up to provide special support for quality improvement and innovation of traditional industries, and for quality tackling of strategic emerging industries. Quality-oriented preferential tax and fee policies and a quality-guaranteed financing system should be constructed. The establishment of a government procurement mechanism with high quality and good price should be accelerated.

The quality personnel fostering system should be improved. Higher education on quality should be promoted, and subjects, majors, and course construction on quality should be perfected. The system would make it clear that enterprises and vocational schools are "dual parties" for training of skilled personnel. A modern apprenticeship system should be promoted to foster high-level technical personnel. A special training mechanism needs to be created to improve the quality competency of entrepreneurs, and provide a knowledge updating platform for highly-qualified entrepreneurs to strengthen their globalized perspective and quality innovation capability. Education and training projects, particularly for quality competence, should be set up. Moreover, by relying on industry associations, a quality education and training network with mutual participation of colleges, research institutes, and enterprises can be constructed.

\subsection{Strengthening the Big Quality working system}

The management system should adapt to the big picture of national development orientation. The prominent contradiction and issue faced by China's current economical operation is the major structural imbalance, especially structural supply and demand imbalance of the real economy. Additionally, the main weakness is a low level of supply quality. In the future, the main task of China's economic work would be to undertake the supply-side structural reform. The main aim of the supply-side structural reform would be to improve the supply quality. It would be essential to ensure all-round improvement of product and service quality for promoting the supply system. To realize quality upgrading of the manufacturing industry, China should focus on improving the supply quality and the product and service quality, and a system guarantee for "Big Quality" is required.

A "Big Quality" working system with Chinese characteristics should be perfected. The overall level of China's manufacturing quality is not high. This situation is a special phase during development and had appeared in the process of industrialization of developed countries, such as the United States, Japan, and Germany. These countries emphasize on quality at a national strategic level for integrated development. China is now at a critical stage of transformation. To promote overall upgrading of manufacturing quality and to realize quality-profit growth of the economy, China should comply with objective laws of quality development, give full play to institutional advantages, and create and continuously perfect a "Big Quality" working system with Chinese characteristics. First, comprehensive focus should be given to quality management. Quality is both a hard power (integration of factors, such as scientific innovation, resource allocation, and labor quality) and a soft power (comprehensive reflection of aspects, such as legal environment, cultural education, and credit construction). We must pay special attention to quality, just like science and education, take comprehensive measures, and promote quality on the whole. Second, coordination of quality management should be strengthened in the following three aspects: coordinating for domestic quality promotion and coping with global quality competition; regarding collaborative measures, coordinating planning guidance at a macro level with market access and law enforcement supervision at a micro level; and with regard to system approaches, coordinating synchronized construction of national quality infrastructure (metrology, standardization, certification and accreditation, and inspection and detection) with quality laws, quality culture, and quality personnel. Third, China should exploit its institutional advantages to pool resources and solve major problems. China should focus on the main direction of supply-side structural reform; upgrade the strategy of strengthening the country through quality; formulate and implement a quality development plan; integrate quality management resources; optimize quality policies and measures; solidify the national quality infrastructure; perfect the quality credit system; promote uniform and authorized quality supervision and law enforcement activities; and fasten the construction of a government-guided, market-oriented, enterprise-dominant, department-interacted, and socially governed working pattern. These measures will accelerate the overall upgrading of China's quality.

China's economic development is entering an era that focuses on quality and centers on promoting quality and benefits of the development. To comprehensively upgrade product quality (or quality of the manufacturing industry), project quality, service quality, and environmental quality, or even growth quality of the whole economy, a scientific, unified, and efficient "Big Quality" 
management system and a corresponding working mechanism will be significant or even crucial.

\section{References}

[1] United Nations Industrial Development Organization. Industrial development report 2016 [R]. Vienna, 2015.
[2] Zhou J Z. Trump's administration may reconstruct the global value chain [N]. China Trade News, 2016-12-08(03). Chinese.

[3] U.S. factories are working again; factory workers, not so much [N]. The Wall Street Journal, 2016-12-18.

[4] Manufacturing Power Strategic Study Group. Manufacturing power strategic study $[\mathrm{M}]$. Beijing: Publishing House of Electronics Industry, 2015.Chinese. 